\title{
Morphological characteristics of osa patients using drug induced sleep endoscopy
}

\begin{abstract}
To evaluate the reliability of drug induced sleep endoscopy (DISE) in identifying levels and degrees of severity of obstruction in sleep disordered breathing (SDB) patients. Patients with obstructive sleep apnea syndrome (OSAS) and habitual snoring diagnosed by polysomnography assessed by history and Epworth Sleepiness Scale (ESS), modified Malampatti index, Friedman staging system, Assessment of the Body mass index (BMI), neck circumference (NC), Müller maneuver (MM) and DISE using the NOHL (nose, oropharynx, hypopharynx and larynx) classification system. Our results revealed 66 patients, 34 males and 32 females with ages ranging from 23 to 58 years. BMI showed that $86.4 \%$ of cases were obese with mean BMI $(35.1 \pm 5.6)$ ranging from $(24-50 \mathrm{~kg} /$ $\mathrm{m} 2)$. NC showed large $\mathrm{NC}(>37 \mathrm{~cm})$ in $100 \%$ of females while it was large $(>43 \mathrm{~cm})$ in only $29.4 \%$ of males. The mean apnea/hypopnea index was $10.7 \pm(11.8 / \mathrm{h})$. Obstruction at oropharyngeal level was $82 \%$ of the patients with grades ranging from 50 to $100 \%$ followed by obstruction at the level of hypopharynx in $68 \%$. Only $13.6 \%$ showed supraglottic obstruction due to flappy epiglottis. Almost all patients showed multilevel obstruction with different grades. We found no correlation between the results of DISE, MM and classic ENT evaluation techniques. DISE treatment recommendations was different in $82 \%$ of patients at the oropharyngeal level and in 39\% at the hypopharyngeal level than those of MM, but was nearly the same regarding supraglottic obstruction.
\end{abstract}

Conclusion: DISE is a reliable tool of upper airway collapse assessment leading to better treatment recommendations for SDB patients.

Keywords: drug induced sleep endoscopy, muller maneuver, sleep disordered breathing, obstructive sleep apnea syndrome
Volume 6 Issue 4 - 2017

\author{
El Tabbakh MT, Fouad T Youssef, Iskander N, \\ Mohamed SM Rashwan \\ Department of Otorhinolaryngology Faculty of Medicine Suez \\ Canal University, Egypt
}

Correspondence: Mohamed el Tabbakh Otorhinolaryngology Department medicine Suez Canal University, Egypt, Tel 0020 1005108110,Email abolobna2@gmail.com

Received: September 03, 2016 | Published: March 31, 2017
Abbreviations: DISE, drug induced sleep endoscopy; SDB, sleep disordered breathing; OSAS, obstructive sleep apnea syndrome; ESS, epworth sleepiness scale; BMI, body mass index; NC, neck circumference; MM, müller maneuver; NOHL, nose oropharynx hypopharynx and larynx

\section{Introduction}

Evaluation of patients with disordered breathing sleep usually include physical examination, ${ }^{1}$ fibro-optic examination with Muller maneuver, ${ }^{2,3}$ lateral cephalometry ${ }^{4}$ and polysomnography. ${ }^{5}$ With the exception of polysomnography most of these methods depend on the static evaluation of the upper airway as they performed on the awake patient. They may be not an ideal method for evaluation of the behavior of the upper airway and its pattern of obstruction during sleep. This inaccurate assessment leads to inappropriate surgical intervention., As obstructive sleep apnea can occur at many levels (multilevel obstruction), and the main regions of obstruction are the soft palate and hypopharynx (actually corresponding to the hypopharynx and the retro-lingual portion of the oropharynx) ${ }^{8}$

Drug-induced sleep endoscopy (DISE) provides a more accurate and real time assessment of the patterns and level(s) of obstruction of the upper airway during sleep. Croft and Pringle described the technique in $1991 .{ }^{8}$ Sleep endoscopy is a technique that consists of pharmacologically inducing sleep in Sleep Disordered Breathing patients to identify the area(s) of vibration and collapse in the upper airway. Drug-induced sleep endoscopy has been shown to be a safe, feasible, and valid assessment of the upper airway. ${ }^{9}$ Improving the method of assessment aim to improve the surgical intervention outcome.

\section{Patients and methods}

\section{Patients}

This study was carried out as a prospective randomized clinical trial study. 66 patients of both sexes who attended the E.N.T. outpatient clinic at the Suez Canal University Hospital were enrolled. Inclusion criteria included: Patients suffering from habitual snoring and patients with a confirmed diagnosis of OSAHS (Apnea hypopnea index: AHI > 10 per hour of sleep) using polysomnography. Exclusion criteria include: Patients unfit for general anesthesia, pregnant, allergy to propofol and patients refusal.

\section{Methods}

I. A thorough history: asking about the main clinical triad for SAHS symptoms including Chronic snoring, Witnessed apneas and Excessive daytime sleepiness or tendency to fall asleep involuntarily in inappropriate situations. ${ }^{10}$ In addition to Other common symptoms and signs of SAHS including: morning headache, episodes of nocturnal asphyxia, diaphoresis, nightmares, restless sleep, insomnia, gastroesophageal reflux, enuresis, decreased libido, personality changes, loss of memory, difficulty in maintaining concentration, affected work/study performance, apathy, irritability, morning nausea, symptoms of depression, chronic tiredness, abnormal movements, frequent falls, cardiovascular events and epileptic crises. ${ }^{11}$

II. The Epworth Sleepiness Scale (ESS) was used as an effective instrument to measure average daytime sleepiness. The ESS differentiates between average sleepiness and excessive daytime sleepiness that requires intervention. ${ }^{12}$ 


\section{ENT Examination:}

A. Anterior rhinoscopy: to evaluate the hypertrophy of the inferior turbinate and exclude other causes of nasal obstruction. Vasoconstriction applied to differentiate between static and dynamic nasal obstruction using oxymetazoline $1 \%$ nasal pack for 10 minutes.

B. Oropharyngeal examination: Soft palate is assessed using the modified Malampatti index. ${ }^{13}$ Inspection of the size of the uvula, size and dorsalization of the tongue and tonsil size (according to Friedman staging system). ${ }^{1}$

C. Measuring the Body mass index ${ }^{14}$ and Neck circumference. ${ }^{15}$

IV. Polysomnography: Was carried out over an average recording period of $8 \mathrm{~h}$. The following parameters were recorded apnea \pm hypopnea index, minimal and average oxygen saturation during polysomnographic analysis, grades of nocturnal snoring (0: no snoring, 1: mild snoring up to $20 \%$ of sleep time, 2 : average, up to $60 \%$ sleep time, 3 : severe: more than $60 \%$ of sleep time). According to the results of polysomnography the patients were assigned to the diagnostic categories of either OSAS or habitual snorers. The criteria for assignment to the group of snorers were an apnea \pm hypopnea index (AHI) below 10, a minimal O2 decrease not falling below $90 \%$ and snoring during polysomnography (grade 2 and 3$){ }^{16}$

V. Müller maneuver: Endoscopic evaluation of the upper airways through the nose, with the patient in the supine position, during which a modified Muller maneuver (forced inspiratory suction with mouth and nose closed). ${ }^{17}$

VI. Drug Induced Sleep Endoscopy: ${ }^{18}$ DISE was performed by using the flexible rhinopharyngolaryngoscopy (11101 RP2, Karl Storz, Germany) on each patient in supine position after doing Muller maneuver in an intervention room. Patients were fasting over the night before the DISE, to prevent regurgitation and aspiration. To reduce salivation, atropine or was administered 30minutes before starting the procedure. A topical anesthetic, with or without a decongestant, was administered to 1 or both nostrils at least 20 minutes before starting the procedure, being careful not to over-anesthetize the pharynx, as the risk of aspiration and coughing increases. The patient was lying in the supine position on the operating table. The position should attempt to mimic sleeping habits at home (e.g., 1 or 2 pillows). The film of the flexible endoscopy was viewed on a screen through a camera (Telecam-C 20212043 PAL, Karl Storz, Germany) connected to a computer for recording. The lights were dimmed and the room was quiet to minimize awaking stimuli.

Repeated bolus infusion of propofol (Diprivan) at $1.5 \mathrm{mg} / \mathrm{kg}$ was given to each patient until sleep begins which was also noticed by the start of snoring with close monitoring of the oxygen saturation doing jaw thrust when obstruction or oxygen desaturation occurred. Anesthetic depth was of key importance. The target depth of sedation was the transition from consciousness to unconsciousness (loss of response to verbal stimulation). Because individuals have differential susceptibilities to propofol, the required dosage can vary widely. Slow stepwise induction was required to avoid over sedation. Deeper levels of sedation were associated with progressive decreases in upper airway dilator muscle tone and neuromuscular reflex activation that both increase airway collapsibility, and the transition to unconscious sedation may be a closer approximation to natural sleep. Once the patient has reached a satisfactory level of sedation, a flexible endoscope lubricated and coated with anticondense was introduced into the nasal cavity. The nasal passage, nasopharynx, velum, tongue base, epiglottis, and larynx were observed. The levels of snoring and/ or obstruction were assessed.

\section{Results}

Total 66 cases were enrolled in this study, 34 males and 32 females with ages ranging from 23 to 58years old. 48 cases $(72.7 \%)$ were non-smokers while 18 cases $(27.3 \%)$ were smokers, mean BMI was $(35.1 \pm 5.6) \mathrm{kg} / \mathrm{m} 2$ (range $24-50 \mathrm{~kg} / \mathrm{m} 2)$, and mean AHI was $10.7 \pm$ $11.8 / \mathrm{h}$

Regarding the symptoms of obstructive sleep apnea we found that $95.5 \%$ of cases were snorers, $86.4 \%$ complaint of insufficient sleeping at night, $90.9 \%$ were sleepy during daytime, $66.7 \%$ had morning headache and $75.8 \%$ had witnessed apnea.

\section{Epworth Sleepiness Scale (ESS)}

Showed 51 patients $(77.3 \%)$ got score $>9$ which means they were excessively sleepy and should seek medical advice, while $22.7 \%$ got enough sleep and weren't sleepy.

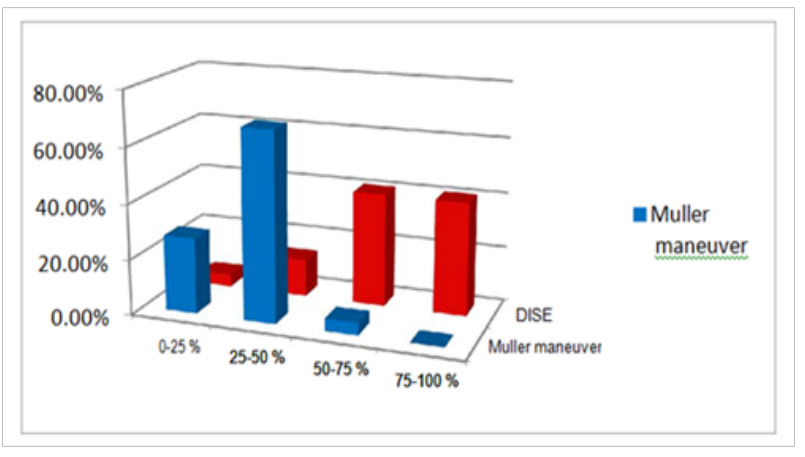

Figure I Degree of oropharyngeal obstruction in MM vs. DISE.

Neck circumference measurement showed large neck circumference $(>37 \mathrm{~cm})$ in $100 \%$ of females while it was large (> $43 \mathrm{~cm}$ ) in only $29.4 \%$ of males MM and DISE were performed and showed different levels and degrees of obstruction. By analyzing the difference between MM and DISE we found the following:

Regarding the or opharyngeal assessment: all the patients showed different degrees of obstruction by DISE, 18 patients got mild degree of obstruction ranging from $0-25 \%$ using $\mathrm{MM}$ while by making DISE to these patients only 3 of them got the same degree, the other 15 patients showed higher degrees of obstruction up to complete obstruction $75-100 \%$ in 6 patients. No patient got high degree of obstruction $50-75 \%$ and only 3 patients showed $75-100 \%$ obstruction by MM while DISE showed obstruction at both levels in 27 patients for each, so DISE helped us to detect high degrees of obstruction 50$100 \%$ which was $54(82 \%)$ patient in the time that MM only detected 3 of them (Table 3 ).

Regarding hypopharyngeal assessment (Table 4): All patients showed different degrees of obstruction using DISE, 30 patients had low degree of obstruction using MM while only half of them got the same degree by DISE and the remaining showed higher degrees, MM showed only 3 patients with 50-75\% obstruction but DISE showed 19 (29\%) patients, also MM didn't show any patient with $75-100 \%$ obstruction but DISE showed this degree in 26 (39\%) patients, so DISE helped us to detect higher degrees of obstruction in comparison to $\mathrm{MM}$ that detected only low degrees. 
Table I Shows Classic ENT Evaluation Results

\begin{tabular}{ll}
\hline Anterior Rhinoscopy & \\
\hline Normal Rhinoscopy & $48(72.7 \%)$ \\
\hline Deviated Septum & $9(13.6 \%)$ \\
\hline Hypertrophied Inferior Turbinates & $9(13.6 \%)$ \\
\hline Modified Mallimpati Index (MMI) & \\
\hline Score I & $3(4.5 \%)$ \\
\hline Score 2 & $10(15.2 \%)$ \\
\hline Score 3 & $24(36.4 \%)$ \\
\hline Score 4 & $29(43.9 \%)$ \\
\hline Tonsil Size* & \\
\hline Grade 0 & $9(13.6 \%)$ \\
\hline Grade I & $30(45.5 \%)$ \\
\hline Grade 2 & $24(36.4 \%)$ \\
\hline Grade 3 & $3(4.5 \%)$ \\
\hline Grade 4 & $0(0 \%)$ \\
\hline Uvula Assessment & \\
\hline Absent uvula & $5(7.57 \%)$ \\
\hline Normal uvula & $40(60.6 \%)$ \\
\hline Long uvula & $21(31.8 \%)$ \\
\hline
\end{tabular}

Table 2 Comparison between Results of Muller Maneuver and DISE

\begin{tabular}{|c|c|c|c|}
\hline & MM & DISE & $P$ value \\
\hline \multicolumn{4}{|l|}{ Oropharynx } \\
\hline \multicolumn{4}{|c|}{ Degree of Obstruction } \\
\hline $0-25 \%(\mathrm{GI})$ & $18(27.3 \%)$ & $3(4.5 \%)$ & $0.040 *$ \\
\hline $25-50 \%(\mathrm{G} 2)$ & $45(68.2 \%)$ & $9(13.6 \%)$ & \\
\hline $50-75 \%(\mathrm{G} 3)$ & $3(4.5 \%)$ & 27 (40.9\%) & \\
\hline $75-100 \%(G 4)$ & $0(0 \%)$ & 27 (40.9\%) & \\
\hline \multicolumn{4}{|l|}{ Hypopharynx } \\
\hline \multicolumn{4}{|c|}{ Degree of Obstruction } \\
\hline $0-25 \%(G I)$ & 30 (45.5\%) & 15 (22.7 \%) & $0.000 *$ \\
\hline $25-50 \%(G 2)$ & $33(50 \%)$ & $6(9.1 \%)$ & \\
\hline $50-75 \%(G 3)$ & $3(4.5 \%)$ & 19 (28.8\%) & \\
\hline $75-100 \%(G 4)$ & $0(0 \%)$ & $26(39.4 \%)$ & \\
\hline \multicolumn{4}{|l|}{ Larynx } \\
\hline \multicolumn{4}{|l|}{ Supraglottic } \\
\hline Positive & $9(13.6 \%)$ & $9(13.6 \%)$ & $0.06 * *$ \\
\hline Negative & $57(86.4 \%)$ & $57(86.4 \%)$ & \\
\hline
\end{tabular}

*Significant at $P$ value $<0.05$

**Insignificant

Table 3 Oropharynx Obstruction Assessment by MM vs. DISE

\begin{tabular}{|c|c|c|c|c|c|c|}
\hline & & \multicolumn{4}{|l|}{ DISE } & \multirow[t]{2}{*}{ Tota } \\
\hline & & $0-25 \%$ & $\begin{array}{l}\mathbf{2 5 -} \\
\mathbf{5 0} \%\end{array}$ & $\begin{array}{l}50- \\
75 \%\end{array}$ & $\begin{array}{l}75- \\
100 \%\end{array}$ & \\
\hline & & (GI) & (G2) & (G3) & (G4) & \\
\hline \multirow[t]{4}{*}{$\begin{array}{l}\text { Muller } \\
\text { Maneuver }\end{array}$} & $0-25 \%(\mathrm{Gl})$ & 3 & 3 & 6 & 6 & 18 \\
\hline & $25-50 \%$ & 0 & 6 & 21 & 18 & 45 \\
\hline & $\begin{array}{l}50-75 \% \\
\text { (G3) }\end{array}$ & 0 & 0 & 0 & 3 & 3 \\
\hline & $\begin{array}{l}75-100 \% \\
\text { (G4) }\end{array}$ & 0 & 0 & 0 & 0 & 0 \\
\hline Total & & 3 & 9 & 27 & 27 & 66 \\
\hline
\end{tabular}

Regarding presence or absence of flappy epiglottis there was a slight difference that was statistically insignificant (Table 5).
Table 4 Hypopharynx Obstruction Assessment by MM vs. DISE

\begin{tabular}{lllllll}
\hline & \multicolumn{3}{c}{ DISE } & & \multicolumn{2}{r}{ Total } \\
\hline Muller & & $\mathbf{0 - 2 5 \%}$ & $\mathbf{2 5 - 5 0 \%}$ & $\begin{array}{l}\mathbf{5 0 -} \\
\mathbf{7 5 \%}\end{array}$ & $\begin{array}{l}\mathbf{7 5 -} \\
\mathbf{1 0 0 \%}\end{array}$ \\
Maneuver & $0-25 \%$ & 15 & 3 & 4 & 8 & 30 \\
& $25-50 \%$ & 0 & 3 & 15 & 15 & 33 \\
& $50-75 \%$ & 0 & 0 & 0 & 3 & 3 \\
& $75-100 \%$ & 0 & 0 & 0 & 0 & 0 \\
Total & & 15 & 6 & 19 & 26 & 66 \\
\hline
\end{tabular}

Table 5 Flappy Epiglottis in MM vs. Flappy Epiglottis in DISE

\begin{tabular}{lllll}
\hline & & \multicolumn{2}{l}{$\begin{array}{l}\text { Flappy epiglottis in } \\
\text { DISE }\end{array}$} & Total \\
\hline & & Positive & Negative \\
\hline Flappy epiglottis in MM & Positive & 3 & 6 & 9 \\
& Negative & 6 & 51 & 57 \\
Total & & 9 & 57 & 66 \\
\hline
\end{tabular}

In the assessment of glottis we got exactly the same results in both tests. Combined pathology was noticed by DISE in the following forms (Table 6): 3 patients had $25-50 \%$ obstruction in the oropharynx, $50-75 \%$ obstruction in the hypopharynx and they also had flappy epiglottis (three levels of obstruction). Six patients $(n=6 / 66)$ showed $50-75 \%$ obstruction in the oropharynx, different degrees of obstruction in the hypopharynx and they also had flappy epiglottis (three levels of obstruction). Fourteen patients (21\%) had $75-100 \%$ of obstruction at both oropharyngeal and hypopharyngeal levels at the same time (two levels of obstruction).

Also all patients had mixed combinations of obstruction degrees at both levels of the oropharynx and hypopharynx.

\section{Discussion}

Frequently, UA collapse occurs at the same time at different levels. Identifying the site and the dynamic pattern of obstruction is mandatory in therapeutical decision- making, and in particular if a surgical therapy option is taken into account. The main pathophysiological event of obstructive sleep apnea hypopnea syndrome (OSAHS) is the apneic collapse of the upper airways (UA). The most frequent sites of pharyngeal collapse are soft palate, lateral pharyngeal walls, palatine tonsils; base of the tongue and the larynx can be involved as a site of obstruction at epiglottis level in most cases. ${ }^{8}$

In 1977 and 1978, respectively, Weitzman et al., ${ }^{19}$ and Hill et al., ${ }^{20}$ were the first to report the use of fiber-optic endoscopy in awake state in order to investigate pharyngeal collapse in patients with sleep apnea.

Later et al., ${ }^{21}$ showed that results of the MM alone should not be considered reliable due to the fact that the findings are not always representative of what really occurs during sleep that is why sleep endoscopy is better as it gives us an accurate dynamic assessment of the UA. Camilleri et al., ${ }^{22}$ have demonstrated the reliable predictive value of pre-operative sleep endoscopy for the successful outcome of UPPP and Lin et al. reported that endoscopic pharyngeal sedated evaluation, in patients with OSAHS, had clinical power to improve the UPPP results. ${ }^{23}$

Recently, DISE has been introduced to overcome the limits of the awake nasopharyngeal endoscopy. It consists of an endoscopy carried out during different steps of sedation obtained by different sedative agents. $^{24}$ 
Table 6 Combined Results of DISE

\begin{tabular}{|c|c|c|c|c|c|c|c|c|c|c|}
\hline & & Oropha & in DIS & & & & & & & Total \\
\hline & & $0-25 \%$ & & $25-50 \%$ & & $50-75 \%$ & & $75-100 \%$ & & \\
\hline & & $+v e^{*}$ & $-\mathrm{ve}^{* *}$ & +ve & -ve & +ve & -ve & +ve & -ve & \\
\hline \multirow[t]{4}{*}{ Hypopharynx in DISE } & $0-25 \%$ & 0 & 0 & 0 & 3 & 0 & 9 & 0 & 3 & 15 \\
\hline & $25-50 \%$ & 0 & 0 & 0 & 0 & 3 & 0 & 0 & 3 & 6 \\
\hline & $50-75 \%$ & 0 & 3 & 3 & 0 & 0 & 6 & 0 & 7 & 19 \\
\hline & $75-100 \%$ & 0 & 0 & 0 & 3 & 3 & 6 & 0 & 14 & 26 \\
\hline Total & & 0 & 3 & 3 & 6 & 6 & 21 & 0 & 27 & 66 \\
\hline
\end{tabular}

*Flappy Epiglottis

**Normal

In our study, ENT examination by the classic ENT evaluation techniques and DISE were done to 66 patients suffering from sleep disordered breathing including habitual snorers and patients suffering from OSAHS diagnosed by polysomnography.

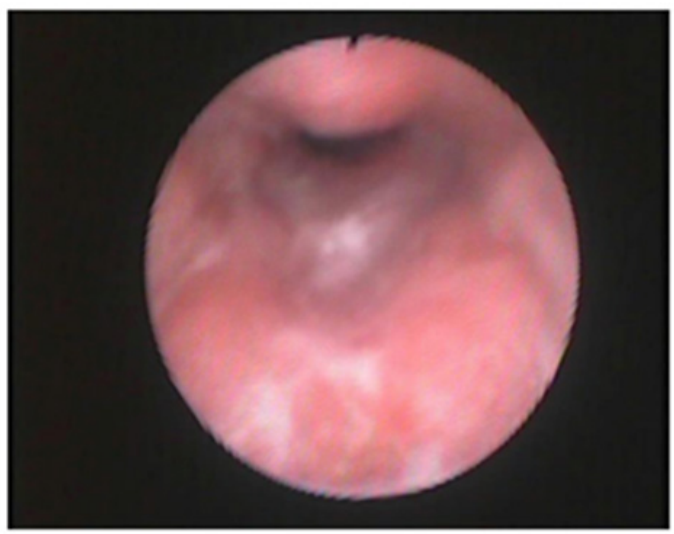

Figure 2 Partial obstruction at the level of soft palate.

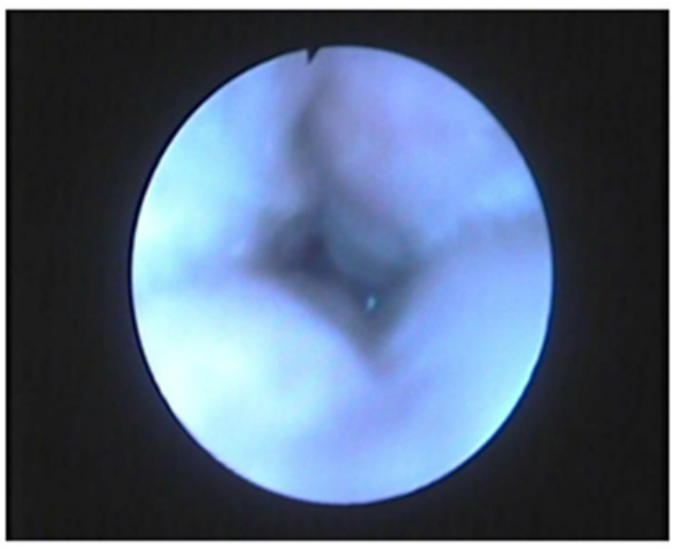

Figure 3 Complete latero-lateral collapse at the level of soft palate especially the tonsils.

We used the NOHL classification system for DISE in the assessment of the upper airway collapse in sleep disordered breathing patients. Vicini $\mathrm{C}$ et al. ${ }^{17}$ were the first to describe and use this classification system for precise dynamic description for the upper airway collapse in sleep disordered patients during sleep.

This study showed that most of the patients had obstruction at the oropharyngeal level, $82 \%(\mathrm{n}=54 / 66)$ of the patients showed from $(50-100 \%)$ obstruction at the level of the oropharynx according to the NOHL classification (table 3). This was consistent with Eichler C et al., ${ }^{25}$ who showed that the most frequent site of obstruction visualized by DISE was the velum (including soft palate, uvula, tonsils, and nearby sections of pharynx) with $93.8 \%(\mathrm{n}=91)$. Also Bachar et al., ${ }^{26}$ showed in the corresponding level (uvulopalatal plane including the tonsils) an obstruction rate of $89 \%(\mathrm{n}=47 / 53)$. Abdullah et al., ${ }^{27}$ divided the sites of obstruction into soft palate and tonsils with an obstruction rate at the palatal level of $87 \%(n=26 / 30)$ and at the tonsil level of $40 \%(n=12 / 30)$. Nearly all patients studied by Steinhart et al. ${ }^{28}$ showed a collapsibility of over $80 \%$ on the level of velum.

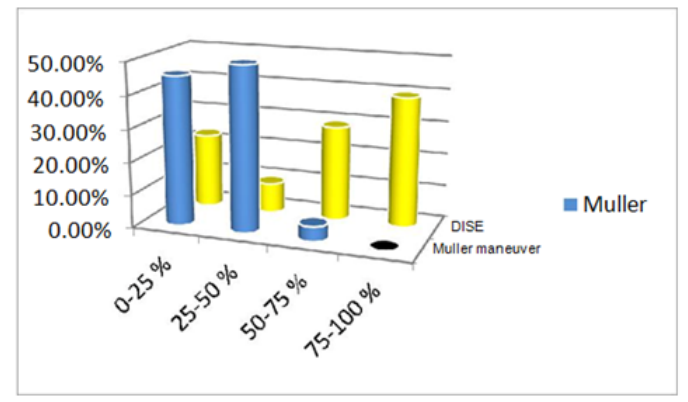

Figure 4 Degree of hypopharyngeal obstruction in MM vs. DISE.

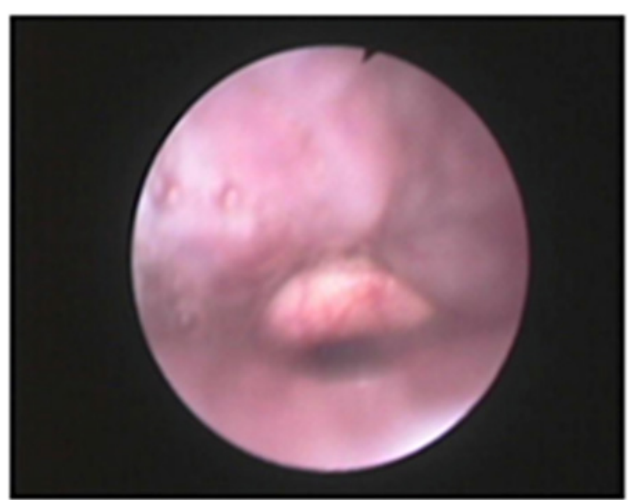

Figure 5 Anterior-posterior pattern of pharyngeal collapse in which a collapse due to anterior pharyngeal collapse against the posterior pharyngeal wall is detected (the base of the tongue against pharyngeal wall during the DISE).

The second most commonly noted obstruction level at high grades of obstruction in our patient group was the hypopharynx in $68 \%$ $(n=45 / 66)$ (table 4). Our results were consistent with those of Eichler $\mathrm{C}$ et al., ${ }^{25}$ who noted that $76.3 \%(\mathrm{n}=74)$ of all patients had obstruction at the same level, second in order after the oropharyngeal level. Other studies showed a highly variable obstruction rate of $13-77 \%$ at this level. ${ }^{8,29}$ 
Only $13.6 \% \quad(n=9 / 66)$ of our patients showed supraglottic obstruction due to flappy epiglottis while Eichler $\mathrm{C}$ et al., ${ }^{25}$ found $32.0 \%(\mathrm{n}=31)$ with an obstruction at the epiglottis level. Results reported by other groups varied substantially between $1 \%$ and $40 \%{ }^{26-28}$ Thus, the frequency and distribution of the different levels of obstruction in our study population is comparable to those of other groups.

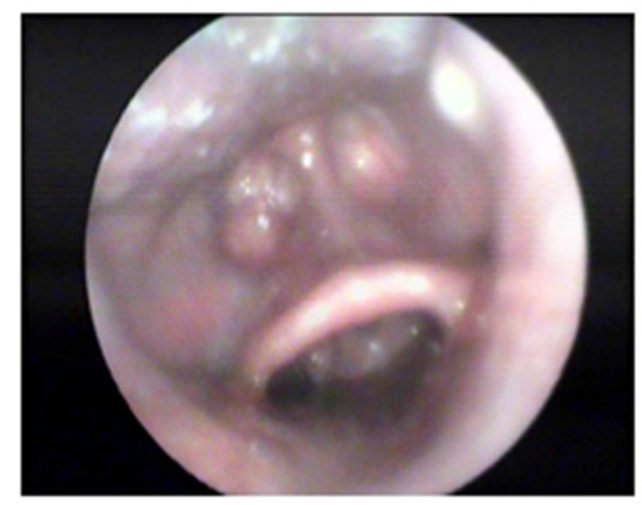

Figure 6 Partial supraglottic obstruction due to flappy epiglottis.

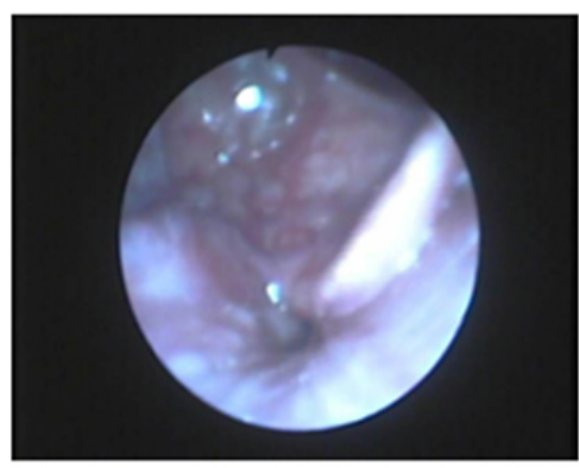

Figure 7 complete supraglottic obstruction due to flappy epiglottis.

We also found that all the patients $(100 \% \%)$ had multiple level obstructions that could not have been suspected during the exploration of the awake patients. Fourteen patients $(21 \%)$ had $(75-100 \%)$ of obstruction at both oropharyngeal and hypopharyngeal levels at the same time (two levels of obstruction). Six patients showed (50 - 75 $\%$ ) obstruction in the oropharynx, different degrees of obstruction in the hypopharynx and they also had flappy epiglottis (three levels of obstruction). For these patients (three levels of obstruction including the hypopharynx) surgery isn't the recommended treatment regimen and they should be placed on CPAP, these findings couldn't be detected by the classic ENT evaluation techniques.

Kezirian EJ et al., ${ }^{30}$ found that three-quarters of the subjects in his study demonstrated multilevel obstruction during DISE. Our results were in agreement with Carrasco $\mathrm{M}$ et al., ${ }^{31}$ who also found that most of the patients involved in their study showed multiple levels of obstruction.

The results of our study were consistent with Carrasco $\mathrm{M}$ et al., ${ }^{31}$ who didn't find a correlation between the exploration of the upper airway carried out on the awake patient by MM and the findings of DISE, suggesting that they cannot depend on the findings of MM without DISE.
Also DISE helped us to know not only the degree of obstruction but also its pattern in the oropharynx and hypopharynx which was as follows:

a. Oropharynx: most patients $75.8 \%$ had concentric obstruction while $9.1 \%$ had antero - posterior obstruction and $15.1 \%$ had latero-lateral obstruction.

b. Hypopharynx: nearly half of patients $48.5 \%$ had concentric obstruction, $19.7 \%$ had antero-posterior obstruction and $31.8 \%$ had latero-lateral obstruction.

Carrasco $\mathrm{M}$ et al., ${ }^{31}$ found that it is useful to describe the anteroposterior or circular morphology of the collapse, as it seems to affect the results of the surgery. Hattori ${ }^{32}$ has reported that the UPPP has a greater success rate when it is carried out in a palate of anteroposterior closure (81.8\% compared with $3 \%$ of success in patients with circular closure). Furthermore he reports a $100 \%$ success rate in patients with collapse due to tonsillar cause. Iwanaga et al., ${ }^{33}$ has also reported a difference between the postoperative results of patients according to the morphology of the collapse, reporting $74 \%$ for the anteroposterior type and 53\% for the circular.

Finally our results helped us to assess DISE as an important diagnostic tool for sleep disordered breathing patients in order to identify the level of upper airway collapse regarding the degree and pattern of obstruction using the NOHL classification system and that the classic ENT evaluation technique including MM can't give us nor an accurate neither a complete UA evaluation so we can't rely on their treatment recommendations while we can rely on the treatment recommendations of DISE as a reliable tool for dynamic UA evaluation during sleep.

\section{Conclusion}

Classic ENT evaluation techniques including MM aren't sufficient or reliable for UA evaluation and can give us incomplete assessment and even faulty treatment recommendations, as they don't describe the dynamic collapse of the UA during sleep.

DISE is a reliable and an accurate tool of UA assessment during sleep and can give us the best treatment recommendations for SDB patients in addition to the avoidance of unnecessary surgical interventions especially in multilevel obstruction patients.

The following advantages of DISE were found:

a. DISE describes all sites of the upper airway involved in the apneic obstruction.

b. DISE aims at showing all the dynamic patterns of pharyngolaryngeal wall collapse, specifying the grading of collapse.

c. By observing patient's parameters (age, gender, BMI, AHI) alone, no prediction of obstruction mechanism or location can be made.

d. DISE has a relevant influence on treatment recommendations.

e. DISE might positively influence success rates of OSA therapy compared to classic ENT evaluation techniques.

\section{Recommendations}

1. DISE should be performed routinely for all SDB patients.

2. DISE should be performed first for any patient planned for upper airway surgical intervention. 
3. We shouldn't rely on the results of classic ENT evaluation techniques including MM in the assessment of SDB patients.

4. We recommend the usage of the NOHL classification system for DISE.

5. Further studies are required in order to compare the treatment outcomes for OSA patients with the treatment recommendations of DISE.

\section{Compliance with ethical standards}

A. All the authors had declared that there are no potential of conflicts of interests and no funding agents of any other financial involvements from any organizations.

B. All authors disclose that there were no funding or any other financial involvements had been participated in this research

C. Informed consent was taken from each patient before participating in the study

D. The Suez Canal university faculty of medicine Ethical Committee approved the conduct of this research under the serial number 681 approved the study.

\section{Acknowledgments}

None.

\section{Conflicts of interest}

Author declares there are no conflicts of interest.

\section{Funding}

None.

\section{References}

1. Friedman M, Ibrahim H, Bass L. Clinical staging for sleep-disordered breathing. Otolaryngol Head Neck Surg. 2002;127(1):13-21.

2. Sher AE, Thorpy MJ, Shprintzen RJ, et al. Predictive value of Muller maneuver in selection of patients for uvulopalatopharyngoplasty. Laryngoscope. 1985;95(12):1483-1487.

3. Doghramji K, Jabourian ZH, Pilla M, et al. Predictors of outcome for uvulopalatopharyngoplasty. Laryngoscope. 1995;105(3 Pt 1):311-314.

4. Petri N, Suadicani P, Wildschiodtz G, et al. Predictive value of Muller maneuver, cephalometry and clinical features for the outcome of uvulopalatopharyngoplasty. Evaluation of predictive factors using discriminate analysis in 30 sleep apnea patients. Acta Otolaryngol. 1994;114(5):565-571.

5. Kushida CA, Littner MR, Morgenthaler T, et al. Practice parameters for the indications for polysomnography and related procedures: an update for. 2005. Sleep. 2005; 28(4):499-521.

6. Skatvedt O. Localization of site of obstruction in snorers and patients with obstructive sleep apnea syndrome: a comparison of fiberopticnasopharyngoscopy and pressure measurements. Acta Otolaryngol. 1993;113(2):206-209.

7. De Benedetto M, Leante M, Graziuso M. La chirurgianellaroncopatiacronica. In: De Benedetto (Ed.), La roncopatiacronica. Official Report of XVI A.O.O.I. Convention. Pisa, Italy, Pacini. 1992;129-149.

8. Croft CB, Pringle M. Sleep nasendoscopy: a technique of assessment in snoring and obstructive sleep apnoea. Clin Otolaryngol Allied Sci. 1991;16(5):504-509.
9. Berry S, Roblin G, Williams A, et al. Validity of sleep nasendoscopy in the investigation of sleep related breathing disorders. Laryngoscope. 2005;115(3):538-540.

10. Capote F, Masa JF, Jiménez A, et al. Manifestacionesclínicasdel SAHS. Métodosdiagnósticos. Síndrome de resistenciaaumentada de la víaaéreasuperior. Arch Bronconeumol. 2002;38(3):21-27.

11. Lioberes P, Duran-Cantolla J, Martinez-Garcia MA, et al. Diagnosis and treatment of sleep apnea-hypopnea syndrome. Arch Bronconeumol . 2011;47(3):143-156

12. Johns MW. Reliability and factor analysis of the Epworth Sleepiness Scale. Sleep. 1992;15(4):376-381.

13. Nuckton TJ, Glidden DV, Browner WS, et al. Physical examination: Mallampati score as an independent predictor of obstructive sleep apnea. Sleep. 2006;29(7):903-908

14. Freedman DS, Khan LK, Serdula MK, et al. Trends and correlates of class 3 obesity in the United States from 1990 through 2000. JAMA. 2002;288(14):1758-1761.

15. Onat A, Hergenc G, Yuksel H, et al. Neck circumference as a measure of central obesity: Associations with metabolic syndrome and obstructive sleep apnea syndrome beyond waist circumference. Clinical Nutrition. 2009;28(1):46-51.

16. Kryger MH, Roth T, Dement WC. Principles and Practice of Sleep Medicine (4th edn), Philadelphia: Elsevier Saunders, USA. 2005.

17. Vicini C, De Vito A, Benazzo M, et al. The nose oropharynx hypopharynx and larynx (NOHL) classification: a new system of diagnostic standardized examination for OSAHS patients. Eur Arch Otorhinolaryngol . 2012;269(4):1297-1300.

18. Hohenhorst W, Ravesloot MJL, Kezirian EJ, et al. Drug-induced sleep endoscopy in adults with sleep-disordered breathing: Technique and the VOTE Classification system. Oper Tech Otolaryngol . 2012;23:11-18.

19. Weitzman ED, Pollak C, Borowiecki B, et al. The Hypersomnia SleepApnea Syndrome: site and mechanism of upper airway obstruction. Trans Am Neurol Assoc. 1977; 102:150-153.

20. Hill MW, Guilleminault C, Simmons FB.Fiber-optic and EMG studies in hypersomnia-sleep apnea syndrome. In: Guilleminault C (Eds.), Sleep apnea syndromes. New York, USA, Liss Inc. 1978;249-258.

21. Pringle MB, Croft CB. A comparison of sleep nasendoscopy and the Muller manoeuvre. Clin Otolaryngol Allied Sci. 1991;16(6):559-562.

22. Camilleri AE, Ramamurthy L, Jones PH. Sleep nasendoscopy: what benefit to the management of snorers? J Laryngol Otol. 1995;109(12):1163-1165.

23. Li W, Ni D, Jiang H, et al. Predictive value of sleep nasendoscopy and the Muller maneuver in uvulopalatopharyngoplasty for the obstructive sleep apnea syndrome. Lin Chuang $\mathrm{Er} \mathrm{Bi}$ Yan Hou $\mathrm{Ke} \mathrm{Za} \mathrm{Zhi.}$ 2013;17(3):145-146.

24. Kezirian EJ. Drug-induced sleep endoscopy. Op Tech Otolaryngol. $2006 ; 17: 230-232$.

25. Eichler C, Sommer JU, Stuck BA, et al. Does drug-induced sleep endoscopy change the treatment concept of patients with snoring and obstructive sleep apnea? Sleep Breath. 2012;17(1):63-68.

26. Bachar G, Feinmesser R, Shpitzer T, et al. Laryngeal and hypopharyngeal obstruction in sleep disordered breathing patients, evaluated by sleep endoscopy. Eur Arch Otorhinolaryngol. 2008;265(11):1397-1402.

27. Abdullah VJ, Wing YK, van Hasselt CA. Video sleep nasendoscopy: the Hong Kong experience. Otolaryngol Clin North Am. 2003;36(3):461-471.

28. Steinhart H, Kuhn-Lohmann J, Gewalt K, et al. Upper airway collapsibility in habitual snorers and sleep apneics: evaluation with druginduced sleep endoscopy. Acta Otolaryngol. 2000;120(8):990-994. 
29. Hessel N, De Vries N. Results of uvulopalatopharyngoplasty after diagnostic workup with polysomnography and sleep endoscopy: a report of 136 snoring patients. Eur Arch Otorhinolaryngol. 2003;260(2):91-95.

30. Kezirian EJ, White DP, Malhotra A, et al. Interrater Reliability of Drug-Induced Sleep Endoscopy. Arch Otolaryngol Head Neck Surg. 2010;136(4):393-397.

31. Carrasco M, Dalmau J, López R, et al. Our findings in the sleep endoscopy exams. Acta Otorrinolaringol Esp. 2005;56(1):17-21.
32. Hattori C, Nishimura T, Kawakatsu K, et al. Comparison of surgery and nasal continuous positive airway pressure treatment for obstructive sleep apnea syndrome. Acta Otolaryngol Suppl. 2003;550:46-50.

33. Iwanaga K, Hasegawa K, Shibata N, et al. Endoscopic examination of obstructive sleep apnea syndrome patients during drug-induced sleep. Acta Otolaryngol Suppl. 2003;550:36-40.

34. Dalmau J, Carrasco LM, Amorós LI, et al. Videofibrosomnoscopia. Acta Otorrinolaringol Esp. 2002;53:502-504. 